Годишњак Филозофског факултета у Новом Саду, Кюига ХХХVII (2012)

Annual Review of the Faculty of Philosophy, Novi Sad, Volume XXXVII (2012)

Snežana Božanić

UDC 355.48/.49(439.5:437.1)“1458/1490““

Filozofski fakultet Univerziteta u Novom Sadu

Originalan naučni rad sbozanic5@gmail.com

\title{
O RATU IZMEĐU MATIJE KORVINA I ĐORĐA POĐEBRADA U SVETLOSTI KAZIVANJA BONFINIJA
}

U radu se prati rat između ugarskog kralja Matije Korvina (1458-1490) i češkog vladara Đorđa Pođebrada (1458-1471), u svetlosti kazivanja Antonija Bonfinija. Italijanski humanista je ovim događajima posvetio kraj prve i najveći deo druge knjige dela Rerum Ungaricarum Decades. On opširno govori o razlozima koji su Matiju naveli na rat protiv tasta, oca njegove pokojne supruge. Posebno naglašava da su Matiju, na pomenuti sukob, naveli verski razlozi, te podrška pape Pavla II i cara Fridriha III. Prati se tok ratnih operacija, Matijin izbor za češkog kralja 1469. godine i događaji do smrti Đorđa Pođebrada tj. izbora novog češkog kralja, sina poljskog kralja Kazimira IV Jagelonca (1447-1492), Vladislava. Dugotrajno i neuspešno ratovanje u Češkoj, kao i zanemarivanje rata sa Turcima u pomenutom periodu, biće razlozi zavere 1471. godine plemstva i sveštenstva u Ugarskoj protiv Matije Korvina.

Ključne reči: srednji vek, Bonfini, Matija Korvin, Đorđe Pođebrad, papa Pavle II

Italijanski humanista i pisac, Antonije Bonfini, u delu Rerum Ungaricarum Decades, u deset kniga, opisuje vladavinu ugarskog kralja Matije Korvina, od 1464. do 1490. godine. Izlažući događaje u svom radu, hronološkim nizom, donosi značajne podatke o ratu Matije Korvina (1458-1490) i češkog kralja Đorđa Pođebrada (14581471). Ovom sukobu posvetio je sam kraj prve i najveći deo druge knjige, narečenog dela.

Pre nego što je izabran za ugarskog kralja, Matija je bio utamničen u Pragu. Narodni kralj Češke, Đorđe Pođebrad (Юрий Подебрад) pustio је Matiju iz zatvora pod uslovom da se oženi sa njegovom ćerkom Katarinom. Odnosi između zeta i tasta, u početku su bili prijateljski i dobri. Pođebradova ćerka Katarina je umrla veoma mlada, za vreme Matijinog pohoda na Bosnu. Bez obzira na ličnu žalost, Matija se 29. marta 1464. godine krunisao legitimnom krunom. Vremenom je došlo do udaljavanja 
i raskidanja bliskih veza između Korvina i Pođebrada.

Pošto je sa uspehom, tokom 1467. godine, ugušio pobunu u Transilvaniji i Moldaviji, kralj Matija se okrenuo rešavanju problema sa Turcima i jeretičkim Česima (Јорга 1934: 106-108). U to vreme, papa Pavle II (Pietro Barbo), pošto je delimično sredio prilike u Italiji, smatrao je Matiju za božijeg izaslanika i velikikog podvižnika, koji je rođen da stane na put jereticima i povede protiv njih krstaški rat.

Češki kralj je bio u nemilosti papske stolice još od vremena papa Pija II (1458-1464). Do nesuglasica i razlaza između njih je došlo oko tumačenja Praških kompaktata. Papa Pije II je pokušao da organizuje krstaški rat protiv Turaka ali je njegova smrt prekinula planirani pohod. Naslednik Pija II, papa Pavle II (1464-1471) se pononovo okrenuo rešavanju češkog pitanja i organizovanju krstaškog pohoda protiv češkog kralja. Novi papa je 1466. godine proglasio Đorđa Pođebrada za jeretika i lišio ga kraljevskog dostojanstva.

Još od tog vremena, papa je, piše Bonfini, često slao Matiji pisma u kojima ga je bodrio da započne rat sa češkim kraljem. Istovremeno, na njega je vršio pritisak i car Fridrih III. Dodatno je Matiju sokolila činjenica da su Turci bili zaokupljeni ratom u Egiptu i Siriji. Ugarski kralj nije zaboravio ni zlodela koja su češki najamnici učinili pod Švehlom, tokom 1465. godine. O ovim događajima Bonfini detaljno piše u u prvoj knjizi dela Rerum Ungaricarum Decades (Bonfinis 1976: 5-7). Istina, dodaje pisac, ugarskog kralja je na rat podstrekivala „urođena slavoljubivost” i činjenica da je „zarad težnje besmrtnosti bio kadar da prezre i najveću opasnost” (Bonfinis 1976: 19). U nastavku, dodaje da ga je na pohod vodila ljubav i obziri verske prirode, te podrška pape i Fridriha III. Papa Pavle II mu je po Jovanu Emonu poslao 50000 zlatnika za rat. Car Fridrih III mu je nudio godišnji prihod Austrije, oružje i opsadnu opremu. Iz pisma koje je Matija poslao Viktoru, sinu Đorđa Pođebrada, doznaje se da su važan povod za rat pružili Hajnrih Lipa i Matija Stajnberg koji su stalno vršili prepade na Ugarsku i inicirali pogranične čarke. Razbesneo ga je i Stefan Ajcinger koji mu je naplatio ogromnu carinu za naoružanje koje je bilo kupljeno u Nemačkoj za rat protiv Turaka.

Tim povodom, Matija je sazvao sabor na kojem se odlučivalo o pohodu protiv jeretika u Češkoj. Čula su se oprečna mišljenja. Jedna struja je smatrala da je najveći neprijatelj Ugarske i dušmanin turski sultan, Mehmed II. Imali su na umu da Ugarska nije bila u stanju da vodi rat na dva fronta i da je u velikoj meri bila 
materijalno i vojno iscrpljena. Sa druge strane, javili su se oni koji su bili mišljenja da jeres koja je zahvatila Češku i Moravsku, svakog trena može da se prelije u Ugarsku. Oni su verovali u Matijinu mudrost i sposobnost. U svakom slučaju, oba rata su bila bogougodna i opravdana. Svi su čekali Matijnu odluku koji je sve vreme ćutao i slušao ih.

Drugu knjigu, dela Rerum Ungaricarum Decades, Bonfini otpočinje opširnim govorom kralja Matije, kojim se obratio prisutnim velikašima, sveštenicima i vojnicima na sazvanom saboru. Prethodno su pročitana pisma pape Pavla II i cara Fridriha III u kojima ga preklinju da ,zaštiti pravu veru i hrišćansku zemlju od jeretičke pošasti, ništa manje opasne od samih Turaka” (Bonfinis 1976: 20). Italijanski humanista, na ovom mestu, umeće veoma opširan govor kralja Matije u kojem on obrazlaže svoje razloge za rat. Naime, Matija podvlači da nije u redu da on vodi rat protiv sopstvenog tasta, koji mu je bio poput oca. Međutim, kao kralj bio je u obavezi da lične razloge podredim javnom interesu. Bojao se češke jeresi, koja se kao pošast nadvila nad granicama Ugarske. Matija je govorio da se treba „povesti za primerom Gospoda i Spasitelja, te ne samo odbaciti sopstveni razum, već žrtvovati i sopstvenu dušu ukoliko tako Bog nalaže" (Bonfinis 1976: 21). Jeretici, namerno mešaju pravoverje sa krivoverjem, njihovi religijski obredi su naopaki i zatrovani, svetinje su poharane, a prava vera do te mere izvitoperena da se „noćne molitve i bdenja izvrću u blud i skrnavljenje” (Bonfinis 1976: 21). Za Matiju, to je rat za spas duša a ne za puki fizički opstanak. Ugri su, od pape i nemačko-rimskog cara pozvani da oslobodite jedan hrišćanski narod od jeretičke zaraze. Posebno se u govoru obraća vojnicima i sveštenicima, koji čine okosnicu ugarskog društva. Većina ljudi u Ugarskoj činili su ratnici koji su po prirodi sazdani za rat. Ugri žive između Turaka koji ih gone u ropstvo i još opasnijih Čeha, koji ih vode u duševnu propast i večito prokletstvo. Sa druge strane, sveštenici ne smeju da dozvole dušmansko širenje jeresi i propast tolikih života. Svi zajedno treba da brane veru Hristovu i iskorene jeretičku pošast. Ukoliko se navedeni razlozi ne uvaže, govori Matija, prema pisanju Bonfinija, svi će biti osuđeni na paklene muke. Matija je sve prisutne podsetio na zadobijene rane u nedavnom sukobu sa Vlasima. Iako je bio ozbiljno povređen, opasnost koja se nadvila nad njihovom domovinom mu vraća snagu i entuzijazam. Skrenuo je pažnju prisutnima na 28 godina pljačkanja od strane Telefa, Giškre, českog bratstva i Švehle, kao i na postupke Hajnriha Lipe, Stefana Ajcingera i 
Matije Stajnberga. Potom naglašava da su Česi ratnički narod, opisuje njihove fizičke osobine kao i sklonost ka ratovanju. Ugarska se, izričit je Matija, ne sprema na rat protiv čitave Češke, već isključivo protiv jeretika. Njegova vojska na svojoj strani ima Božiju podršku i zaštitu, podršku pape i rimsko-nemačkog cara. Da bi umirio sve prisutne, podsetio ih je kako je turski sultan zaokupljen ratom u Egiptu i Siriji, te im sa te strane ne preti opasnost. Rat „donosi spas i dobrobit svima, zahvalnost cara i pape, te slavu i besmrtnost Ugarskoj” (Bonfinis 1976: 23) Na kraju obraćanja, moli Isusa Hrista da se jeretici vrate pravoj veri a da njihovi dušmani Turci budu poraženi. Pošto je završio tako nadahnut govor, svi prisutni su se priklonili njegovom stavu i doneli odluku da započnu rat.

Istovremeno, stigli su turskih emisara na čelu sa Nikolom Iločkim, koji su u ime turskog sultana nudili primirje. U pitanju je bila, nastavlja Bonfini, turska lukavost jer je primirje trebalo da im zagarantuje red u Evropi kako bi nesmetano vojevali u Aziji. Kao pregovarača, Matija im je poslao Vlada Drakula od kojeg su Turci zazirali. Navodno, od straha, pregovarači nisu smeli ni da ga pogledaju u oči. $\mathrm{Na}$ sve to, ugarski vladar je odbio ponudu poslanstva jer njemu ne dolikuje sklapanje mira sa Turcima. Pre nego što je raspustio sabor, Matija je bogato darivao plemiće koji su učestvovali u nedavnim borbama, u Moldaviji. Naročito je bogato darivao Nikolu Banfija.

Dakle, Bonfini u prvi plan ističe da je Matija bio motivisan verskim razlozima za rat sa jeretičkim Česima. Samo na jednom mestu spominje njegovu urođenu slavoljubivost. Međutim, razlozi su bili znatno složeniji i dublji.

Više od dve decenije, kralj Matija je posvetio nastojanjima da utemelji podunavsku imperiju, koju je smatrao veoma važnom (Hanák 1995: 51). Njegova politika širenja na zapad ga je dovela u sukob sa češkim kraljem (Дворник 2001: 293294). Prema nekim pretpostavkama, kako piše Peter Rokai, kralj Matija je sanjao da postane car (Рокаи 2002: 161). Ukoliko bi se domogao češke krune, postao bi jedan od kneževa izbornika i samim tim bi mogao uticati na izbor nemačkog kralja i cara. Na rat ga je posticao i papa Pavle II, za kojeg su Pođebrad i utrakvisti podjednako bili opasni za hrišćane kao i Turci (Лонгворт 2002: 341-342). Ne treba zaboraviti da je zbog problema sa Viktorom, sinom Đorđa Pođebrada, koji je upao u Austiju, Fridrih III tražio pomoć od kralja Matije. Sa druge strane, uvek dobro obavešten, Mehmed II je znao da su rascepkanost i međusobna nesloga hrišćanskog sveta bili njegovo 
najjače oružje. U tom trenutku, on nije imao razloga da se plaši ugarskog kralja već se okrenuo rešavanju bitnijih problema (Бабингер 1968: 243-244). Mehmedova zaokpljenost na ratištu u Aziji je dodatno motivisala Matiju da krene u krstaški rat protiv čeških jeretika.

Četvrte godine od krunisanja, ugarski kralj je započeo rat sa Đorđom Pođebradom. Kralj Matija je iz Egra otišao za Budim a potom za Pizonij. Vršio je regrutaciju, formirao pomoćne vojne odrede te je izdao zapovest da se plemići i sveštenstvo priključe ratu sa svojim četama. Tu mu se pridružio biskupa Ferare, Lavrencije Roborela. Ugarski kralj je izdao edikt kojim se anatemišu svi jeretici i njihove pristalice na teritoriji Češke, Moravske i Šlezije.

Ni Pođebrad nije mirovao. Iščekivao je rat ,sa ciljem da odbrani titulu i lična religijska uverenja" (Bonfinis 1976: 25). Uskoro se obreo u Moravskoj, gde je upravljao njegov sin Viktor.

Bonfini tvrdi kako su se mnogi stanovnici Moravske i Šlezije uplašeni ediktom odrekli jeresi i „povratili svoj katolički karakter” (Bonfinis 1976: 26). Međutim, u utvrđenjima su se i dalje držali malobrojni jeretici.

Sa trupama, Matija je ubrzo podigao logor na obali Morave, na mestu gde njen tok razdvaja Ugarsku od Moravske i omeđuje granicu gornjeg dela Austrije. Čitavih mesec dana nije došlo do bitke. Pisac pravi interesantnu paralelu između Korvina i Pođebrada. Oba vladara su bili mudri i odvažni ljudi ali podjeknako zabrinuti. Razlika je bila velika u njihovim godinama. Pođebrad se plašio ,vatrenosti početnika” a Matija je „strepeo od iskustva starijeg”. Iako su razgovarali na obali Morave i prisećali se nekadašnje ljubavi, pale su teške reči. Matija je tasta optuživao za krivoverje i paganštinu a ovaj je pak njegov postupak nazivao bezbožnim. Iako se, po Bonfiniju, Pođebrad čas ulagivao i govorio lepe reče a onda besneo i pretio, Matija je „odbio molbe i zavet prijateljstva od Pođebradovih izaslanika” (Bonfinis 1976: 26). Pođebrad se sa trupama povukao dok je Viktora ostavio da brani grad Trebič.

U Matijinoj pratnji su se nalazili Nikola Čupor, erdeljski vojvoda, Stefan Batori, palatin Mihailo, kapetan Blaž, Pavle Kinjiži, despot Vuk, Nikola Banfi, obojica nadbiskupa, Ivan Česmički i niz drugih uglednih plemića.

Veliki humanista Bonfini, na ovom mestu poredi Matijinu pratnju sa junacima iz Trojanskog rata. On „Emerika poistovećuje sa Odisejem ili Palamedom, Stefana sa 
Agamemnonom, Pavla sa Ajantom, Čupora sa Diomedom, Mihaila sa Nestorom, a sam Matija bio je slika i prilika Ahilova" (Bonfinis 1976: 27). Ugarski kralj je za sa saborce imao sjajne i neverovatne junake, rečit je italijanski pisac.

Grad Trebič je bio zauzuet neverovatnom brzinom. Nakon podmetnug požara, za svega dva sata ovo utvrđenje je palo a Viktor koji je tu bio stacioniran se povukao u planine sa 900 vojnika. „Na praznik Pashu”, Matija je započeo opsadu novog Viktorovog utočišta. Prestupne 1468. godine Uskrs je bio 17. aprila (Grotefend, 202). Dakle, ove borbe su vođene sredinom aprila. Iako je Matija bio uspešan, Viktoru je pošlo za rukom da pobegne. Zbog ovog incidenta, ugarski vladar je strogo kaznio prestupnike.

Matijina vojska je potom krenulo u prestonicu Moravske, Brno. Prekrsani gradić, smešten u ravnici, bio je opasan zidinama. Tu je bilo utvrđenje Špilberk, teško osvojivo zbog svog položaja i brojnih jeretika. U grad je uputio glasnika. Ukoliko se senat izjasni da je veran papi treba širom da otvori svoja vrata, u suprotnom počeće sukob. Bonfini, na ovom mestu, donosi deo konačnog odgovora senata. U njemu se kaže da su oni sledbenici ,prave vere i rimske dogme”. U teškim vremenima, bili su prinuđeni da istrpe vlast jeretika ali to nije uticalo na njihove verske stavove. Od Matije „branitelju prave vere katoličke” zatražili su da ih zaštiti od tereta ropstva. Želeli su da ih on predvodi u otporu jereticima. Ponudili su zemlju, novac, sva materijalna dobra i ljudstvo ,zarad plemenitih težnji i nauma Njegove svetosti pape i kralja Matije" (Bonfinis 1976: 28). Bili su spremni da otvore kapije grada i prime Matijine trupe, te da ovi preuzmu vlast kad god požele.

Ovaj odgovor je Matija primio sa oduševljenjem. Pozdravio je njihovu istrajnost u pravoj veri i što su izabrali papu umesto češkog kralja. Na taj način su, beleži Bonfini, „,spasili sopstvene duše od nepovratne propasti” (Bonfinis 1976: 29). Matija je obećao gradu nekadašnje privilegije i punu slobodu. Posebno je naglasio da će zaštiti Brno od vojnih operacija i da neće naškoditi lokalnoj trgovini. Narednog dana, u zavisnosti od od društvenog statusa, Ugrima je bio obezbeđen adekvatan smeštaj u gradu.

Osam dana nakon praznika Sanguinis Christi (Tjelovo), Matija je pristupio opsadi Špilberka. Indirektno, može se utvrditi tačan datum ovih operacija. Naime, Tjelovo pada u četvrtak posle praznika Presvetog Trojstva. To je deveti četvrtak nakon Uskrsa. Narečene godine, Tjelovo je bilo 16. juna. Dakle, opsada je počela 
nedelju dana kasnije, tj. krajem juna, i trajala je oko devet meseci.

Ubrzo je pod Brno stigao češki kralj. Italijanski humanista piše, kako je Matija bio u poziciji da napadne Pođebrada koji je prošao pored njegovog logora ali to nije učinio. Češki kralj mu je dobacivao kako pod krinkom odbrane pravoverja želi da se dokopa njegove krune. Nije ga vodila, nastavljao je Pođebrd, na sukob religija već ambicija i želja za vlašću. Na to mu je Matija, obrativšimu mu se sa oče, odgovorio kako se protiv njega vodi verski rat jer je neprijatelj hrišćanstva. Odbio je tastovu ponudu da spor reše međusobnom tučom jer on nije seljak. Vladari se ogledaju na megdanu ali Đorđe Pođebrad tu ponudu nije prihvatio. Bonfini konstatuje, kako je radi sopstvene zaštite, tih dana, Matija sve vreme nosio pancir. To svakako može da uputi na zaključak da je njegov život bio ugrožen.

Ubrzo su povedeni pregovori između tasta i zeta. Predloženo je da se verski spor razreši dvobojem dvorskih luda. Sve to se odvijao na užas i pred očima papinog legata. Ova interesantna epizoda, koju donosi Bonfini i ukoliko joj je moguće verovati, svedoči o neozbiljnosti i poigravanju sa važnim verskim pitanjem. Pregovori su ostali bez očekivanog rezultata i vladari su se povukli.

Pošto je pod Špilberkom ostavio kapetana Blaža i Pavla Kinjižija, Matija se uputio u čuveni moravski grad Olomuc. Stanovništvo ga je dočekalo sa ovacijama i oduševljenjem. Radovali su se dolasku branitelja slobode i prave vere. Ugarski kralj je zauzeo okolne gradove od kojih su neki bili opljačani.

Krajem 1468. godine, Matija je napustio Moravsku i odlučio da prezimi u Budimu. Bonfini piše, kako su Bečlije očekivale da će proći kroz njihov grad ali je on to odbio iz ,ljubavi i poštovanja prema caru Fridrihu”.

Iz drugih izvora se zna, da je Matija objavio 31. marta 1468. godine rat Đorđu Pođebradu. Bonfini ne donosi podatke o broju Matijine vojske. On je na Moravsku krenuo sa 16000 vojnika i 50 topova. Za srpsku istoriografiju je veoma važan podatak da je despot Vuk predvodio odred od 1000 vojnika (Ивић 1929: 17). U Matijinoj pratnji se nalazio i austrijski velikaš, Ulrih od Grafeneka. On je svojevremeno trebao da predvodi hrišćansku vojsku u borbi protiv Turaka. Njemu je čak bio ustupljen Beograd za pripremanje vojnog pohoda, do kojeg nije došlo (Калић 1967: 192-193). Među mnogobrojnim plemićima nalazili su se i grofovi od Sv. Jurja i Bozina kao i Zdenko Šternberg, vođa katoličke lige u Češkoj (Klaić 1973: 92).

U Ugarsku je kralj Matija stigao na praznik arhangela Mihaila. Sve vreme 
je posvetio prikupljanju pomoći za trupe koje su pod Emerikom ostale u Moravskoj. Tek po njegovom povratku, sredinom februara 1469. godine Špilberk je osvojen.

„Druge godine češkog rata”, Matija je krenuo u Olomuc da preuzme odgovarajuće titule. Na saboru u Olomucu (Olomic), katolički orijentisani Česi i Moravci proglasili su ga legitimnim kraljem Češke. U Šleziji je primljen sa neskrivenim oduševljenjem. Vroclav na Odri a potom i drugi gradovi zakleli su mu se na vernost i odanost. Italijanski pisac ne beleži datum krunisanja. Matija je krunisan 3. maja 1469. u Olomucu za češkog kralja.

Bonfini ne navodi u svom delu da Matijino krunisanje nije primljeno sa oduševljenjem kod saveznika. Nezadovoljan je bio Fridrih III, nemački kneževi kao i papa Pavle II (Рокаи 2002: 164). U međuvremenu, mudri Đorđe Pođebrad je za svog naslenika imenovao sina poljskog kralja Kazimira IV Jagelonca (1447-1492), Vladislava, pod uslovom da njegovim sinovima ostanu njihove oblasti.

Upravo tada, po Bonfiniju, posejano je prvo seme razdora između Matije i cara Fridriha III. Naime, Matija je poslao u Beč Mihaila Ostrogonskog da preuzme od rimsko-nemačkog cara obećanu novčanu pomoć (jedan godišnji danak Austrije) i odred od 1000 vitezova. Od obećanog, car Fridrih III ništa nije ispunio. Na ovom mestu, Bonfini objašnjava uzrok kasnijeg rata između ova dva vladara. Činjenica da je bio izigran, toliko je najedila Matiju da „njegov gnev nikako nije jenjavao” i to ga je kasnije navelo da okupira Austriju.

Po povratku iz Šlezije, Matija se sukobio sa Pođebradovim sinom Viktorom. Ovaj je, u međuvremenu, zauzeo grad Vesele i pravio Ugrima probleme. Bonfini opisuje kako je Matija Korvin okružio bedeme grada opsadnim spravama i bronzanim topovima. Danonoćno je tukao grad i na kraju ga zauzeo a Viktora zarobio. Brat njegove pokojne žene ga je molio za milost. Bonfini, opet, u stilu antičkih uzora, umeće govor kralja Matije kojim se obratio Viktoru. Oslovivši ga sa brate, spočitavao mu je što je zastranio i skrenuo sa Hristovog puta. „Kad tako mora, bolje je odreći se rođenog oca nego Isusa!”, rekao je Matija. Tu je ugarski kralj, piše italijanski humanista, pokazao veliku milost. Rešio je da zbog rođačkih veza i bliskosti poštedi Viktora. Ostavio mu je titulu i ugled. Opomenuo ga je da postane „verni sledbenik prave $\mathrm{i}$ istinite dogme Rimske crkve” (Bonfinis 1976: 32). Viktor je ostao zadivljen i zatečen kraljevom milostivošću, tvrdi Bonfini. Pred početak zime, Matija se sa Emerikom, palatinom Mihailom i drugim plemićima i sveštenim licima vratio u 
Ugarsku. Tako se, po italijanskom piscu, završila druga godina češkog ratovanja.

Pokušavajući možda da opravda Matijnu zaokuplenost češkim pitanjem, Bonfini donosi vesti o Mehmedu II i njegovim borbama. Imajući sve to u vidu, on konstatuje da je Matija ispravno postupio kada je prihvatio pohod na Češku jer je Mehmed „u Aziji imao pune ruke posla” (Bonfinis 1976: 33).

Početkom proleća 1470. godine, Matija se ponovo obreo u Moravskoj. Kod utvrđenja Jaurin, primio je vest da je umro njegov tast. Prema pričanju koje je čuo, piše Bonfini, Pođebrada je strašno pogodila vest o zarobljavanju sina, pao je u postelju i umro. Matiju je ta vest čak na suze nagnala. Ni Bonfini nije siguran da li je Matija istinski tugovao ili je ,vešto odglumio žalost” (Bonfinis 1976: 33). Đorđe Pođebrad je umro 22. marta 1471. godine, prema nekim izvorima od vodene bolesti.

Sad se postavilo pitanje izbora novog češkog kralja. Matija je odmah pohitao u Jihlavu da pošalje pregovarače na sabor. Nastojao je da pridobije lokalne plemiće mitom i obećanjima kako bi zatražio krunu. Na sabor u Kutnu uputio je delegaciju na čelu sa sa erdeljskim vojvodom Nikolom Čuporom. Pored njega na presto su pretendovali Poljaci, sinovi Đorđa Pođebrada a bio je zainteresovan i rimskonemački car.

Ugarska delegacija nije primljena na očekivan način. Njegovi emisari su tvrdili da Korvinu kraljevsku titulu garantuje sam papa Pavle II, te su istakli poslovičnu povezanost Ugarskog i Češkog kraljevstva. Posebno su naglasili da skorašnji rat nije bio pokrenut iz osvajačkih pobuda, već sa najplemenitijom namerom vraćanja slobode češkim vernicima. Obećali su slobodu i ukidanje svih poreza ukoliko Matija bude izabran za kralja. Njegovi pregovarači su tokom izlaganja prekidani gunjđanjem i mrštenjem. Sve je bilo veoma neprijatno. Nisu bolje prošli ni izaslanici Fridriha III. Dosta pristalica su imali sinovi Đorđa Pođebrada ali Viktorovo zarobljavanje je stvorilo dodatni problem. Pođebrad je bio „miljenik običnog naroda” a njegovu smrt su sinovi teško podneli, piše Bonfini (Bonfinis 1976: 35).

$\mathrm{Na}$ kraju su se prisutnima obratili izaslanici poljskog kralja Kazimira IV. U stilu antičkih retora, Bonfini u svoje delo ubacuje njihov dug i nadahnut govor. Istakli su prijateljstvo i poslovičnu povezanost poljskog i češkog naroda, bliskost jezika, običaja i rodbinske veze. ,Sva znamenja, proročanstva i zvezde ukazuju na Vladislava kao novog kralja Češke”, smatrali su poljski poslanici. Isticali su da je Vladislav legitimni naslednik češke krune koji ima plemenito poreklo. Sin poljskog kralja je 
bio veoma obrazovan, blage naravi, saosećajan i skroman. U slobodno vreme je učio ratničke veštine. „Mnoge je crte i vrline nasledio od Ladislava, Kazimira, Karla i Žigmunda, a uz sve to nema u njega ni truna zajedljivosti ili oholosti”, govorili su emisari, po Bonfiniju (Bonfinis 1976: 36) Oni su molili prisutne „da uzmu u obzir i ljudske i Božije zakone, te da Vladislavu dodele krunu koja mu po naslednom pravu i pripada" (Bonfinis 1976: 37). Ukoliko postupe umno i pravično, Česi će time smanjiti broj svojih neprijatelja i postići razrešenje problema na obostranu korist Češke i Poljske. Izlaganje poljske delegacije je ostavilo snažan utisak na plemiće. Oni su smatrali da je mladi Vladislav kao stvoren za ,uspostavljanje mira u Češkoj” i svoju odluku su brzo objavili (Bonfinis 1976: 37). Za novog českog kralja izabran je sin poljskog kralja Kazimira IV, Vladislav.

Matijina dugotrajna zaokupljenost na češkom ratištu bez vidljivih rezultata i zanemaraivanje rata sa Turcima izazvaće opšte nezadovoljstvo plemstva i sveštenstva u Ugarskoj. Na čelu urote protiv ugarskog kralja 1471. godine našli su se ostrogonski nadbiskup Ivan Vitez od Sredne (Johannes Vitéz de Zredna) i Ivan Česmički (Janus Panonius). Pošto je sa uspehom ugušio pobunu, Matija je nastavio rat sa Jageloncima do 1478. godine.

\section{LITERATURA:}

Бабингер, Франц (1968). Мехмед Освајач и његово доба. Нови Сад: Матица српска.

Бабић, Сава (2009²). Мађарска циивилизаиија, увод у хунгарологију. Сента: Завод за културу војвођанских Мађара.

Bonfinis, Antonije (1976). Rerum Ungaricarum Decades, tomus IV-pars II. Budapest: Akademiai Kiado.

Grotefend, Herman (2006). Računanje vremena u nemačkom srednjem $i$ novom veku. Novi Sad: Stylos.

Дворник, Френсис (2001). Словени у европској историји и циивилизацији. Београд: Clio.

Јорга, Никола (1934). Историја Румуна и њихове изивилизаџије. Вршац: Југословенска штампарија М. П. Стефановић.

Калић, Мијушковић Јованка (1967). Београд у средњем веку. Београд: 
CK3

Klaić, Vjekoslav (1973). Povijest Hrvata, od najstarijih vremena do svršstka XIX stoleća, knjiga četvrta. Zagreb: Nakladni zavod MH.

Kratohvil, Miloš (1964). Čehoslovačka. Prag: Orbis.

Лонгворт, Филип (2002). Стварање Источне Европе, од преисторије до посткомунизма. Београд: Clio.

Рокаи, Петер, Золтан Ђере, Тибор Пал, Александар Касаш (2002). Историја Мађара. Београд: Clio.

Hanák, Péter (1995). Povijest Mađarske. Zagreb: Barbat.

Ћирковић, Сима (1970). О деспоту Вуку Гргуревићу. Зборник Матице српске за ликовне уметности. 6: 283-290.

Snežana Božanić

A. BONFINIUS ON THE WAR BETWEEN MATTHIAS CORVINUS AND GEORGE OF PODEBRADY

\section{Summary}

A. Bonfinius, an Italian humanist, in his work Rerum Ungaricarum decades describes the reign of Matthias Corvinus [1458-1459] in considerable detail, covering the period from his coronation until his death. Narrating the facts, Bonfinius also gives us important insight on Matthia's war against the Bohemian king George of Podebrady [1458-1471]. He elaborates on Matthia's reasons to start the war and then describes all relevant military operations until George's death, i.e. until a new king was elected. While insisting on justifying Matthia's invasion of Bohemia merely by faith matters - which was not completely true, Bonfinius still provides us with an objective description of military operations. A long-lasting and rather futile war campaign was soon to provoke a rebellion against the king, headed by the chief dignitaries. 